\title{
Contribution To Comprehensive Study Of Aluminium Alloy Aa 5083 Corrosion Induced By Elemental Mercury In LNG Industries.
}

\author{
D.Zerouali ${ }^{*}$, Z. Derriche And M.Y.Azri \\ Department of Chemistry, Faculty of Sciences, Laboratory of materials, \\ University of Sciences \& Technology of Oran \\ U.S.T.O. BP -1505 el M'naouer Oran 31000 -Algeria \\ djizeroual@yahoo.fr - Phone (213)41582268
}

\begin{abstract}
Corrosion induced by elemental mercury in aqueous media of industrial Aluminium alloys AA5083 used in heat exchanger industries of natural gas liquefaction has been studied by linear sweep voltammétry on rotating amalgamated disk electrode. Corrosion process depends on:

- Chemical processes of amalgamation of aluminium with mercury.

- Diffusion process of aluminium in amalgam.

- Electrochemical oxidation of aluminium on amalgamated Interface/water.
\end{abstract}

The diffusion step appears different from that usually found in studies of aqueous corrosion and was not dependent on rotation of electrode but on diffusion of dissolved aluminium in the amalgam before the electrochemical oxidation of amalgamated metal. This is the limiting step of the process at stationary phase of the chemical amalgamation. This occurs at contact time mercury-aluminium longer than $36 \mathrm{~min}$.For shorter times less than $30 \mathrm{~min}$, chemical amalgamation controlled the process. Characteristic parameters of electrochemical behaviour of amalgamated electrodes were investigated: time of cathodic deposit of mercury, time of immersion of electrode in electrolyte before polarisation as well as potential scanning rate.

\section{INTRODUCTION}

Aluminium alloys are successfully used in industries because they have a good corrosion resistance, good thermal and electrical conductivity and low density, which make them very competitive material for the heat exchangers in liquefaction of natural gas industry.
However, impurities like moisture and mercury ${ }^{1}$ which meet in different layers of natural gas and interact with the metal equipments and sometimes cause a significant corrosion ${ }^{2}$.

Aluminium alloys weakly resist corrosion in aqueous medium in the presence of mercuric compounds because aluminium 
and its alloys are very reactive when they are not protected by their oxide film ${ }^{3}$.

The mechanism of reactivity is due to the adsorption of mercury, formation of amalgam film and activation of aluminium surface ${ }^{4}$.

Many interesting studies of mercury elimination are in progress. These results are not satisfactory because they do not allow a complete elimination of mercury. Concentrations of about 10 nanograms of mercury per normal cubic meter of gas and more are frequently encountered ${ }^{5}$ and corrosion appears after physical adsorption and local concentration of residual mercury in the equipments .

Mechanism of corrosion depends on many factors like adsorption of mercury on aluminium surface, electrochemical oxidation and intergranular diffusion ${ }^{6}$ of mercury in aluminium bulk. However, it appears that diffusion of aluminium in amalgam can be the limiting step of corrosion process.

Electrochemical behaviour of amalgamated industrial aluminium alloy type AA 5083 in aqueous medium containing chloride ions was investigated . Single voltamograms were plotted to identify the determinant stage of the process of corrosion.

\section{EXPERIMENTAL}

The samples were supplied by the Algerian natural gas industry and have a chemical composition data given in Table
Samples were mechanically formed with a cylindrical form of $3 \mathrm{~mm}$ diameter. These samples were inserted under press in Teflon ends adapted to an EDX type rotating disk electrode.

Electrolytes were prepared from doubly distilled water by the addition of $\mathrm{KCl}$ crystals to $1 \mathrm{M}$ concentration for all experiments. $\mathrm{pH}$ was adjusted to approximately 7 by the addition of $\mathrm{HCl}$ or $\mathrm{KOH}$.All reagents were PROLABO products of analytical grade .

Amalgamated electrodes were prepared separately by cathodic deposition of mercury on mechanically and chemically cleaned surfaces of the samples at a constant potential $\mathrm{E}=-0,15 \mathrm{volt} / \mathrm{ECS}$ using $10^{-4} \mathrm{M} \mathrm{HgCl}_{2}$ solution Time of mercury deposition was 6-48 min according to experiments. Temperatures, measured before and after each experiment, were approximately $20^{\circ} \mathrm{C} \pm$ $1{ }^{\circ} \mathrm{C}$.

Voltammograms were plotted using a Tacussel 40 -1X type potentiostat driven with pilot type Servovit and registred on $\mathrm{XY}$ table model Leybold. Saturated calomel reference electrode (SCE) and counter-electrode of $2 \mathrm{~cm}^{2}$ area of platinum plate were used.

Scans started from cathodic potential Ei $=-1.8$ volt $/ \mathrm{SCE}$ to an anodic potential $\mathrm{E}_{\mathrm{f}}=-0.8$ volt $/ \mathrm{SCE}$. Rotations of electrode were $5000 \mathrm{rpm}$ for all experiments. 1.

Table 1. Chemical composition of aluminium alloy type AA5083

\begin{tabular}{cc}
\hline Element & \%mass \\
\hline $\mathrm{Mg}$ & $4-5$ \\
$\mathrm{Zn}$ & 0.25 \\
$\mathrm{Si}$ & 0.4 \\
$\mathrm{Fe}$ & 0.4 \\
$\mathrm{Cu}$ & 0.1 \\
$\mathrm{Mn}$ & $0.4-1$ \\
$\mathrm{Ti}$ & 0.25 \\
$\mathrm{Cr}$ & $0.05-0.25$ \\
Other & 0.15 \\
$\mathrm{Al}$ & Remainder
\end{tabular}




\section{RESULTS AND DISCUSSION}

Figure 1 curve a shows an electrochemical behaviour of non amalgamated electrode in $1 \mathrm{M} \mathrm{KCl}$ at $\mathrm{pH}=7$ and temperature $20^{\circ} \mathrm{C} \pm 1^{\circ} \mathrm{C}$. Potential window was limiting to $\mathrm{E}=$ 1 volt/SCE in the anodic side by aluminium pitting corrosion and $\mathrm{E}=-1.8$ volt/SCE in the cathodic side by hydrogen reduction. This result showed a classical electrochemical behaviour of aluminium and its alloys in aqueous solutions containing chloride ions.

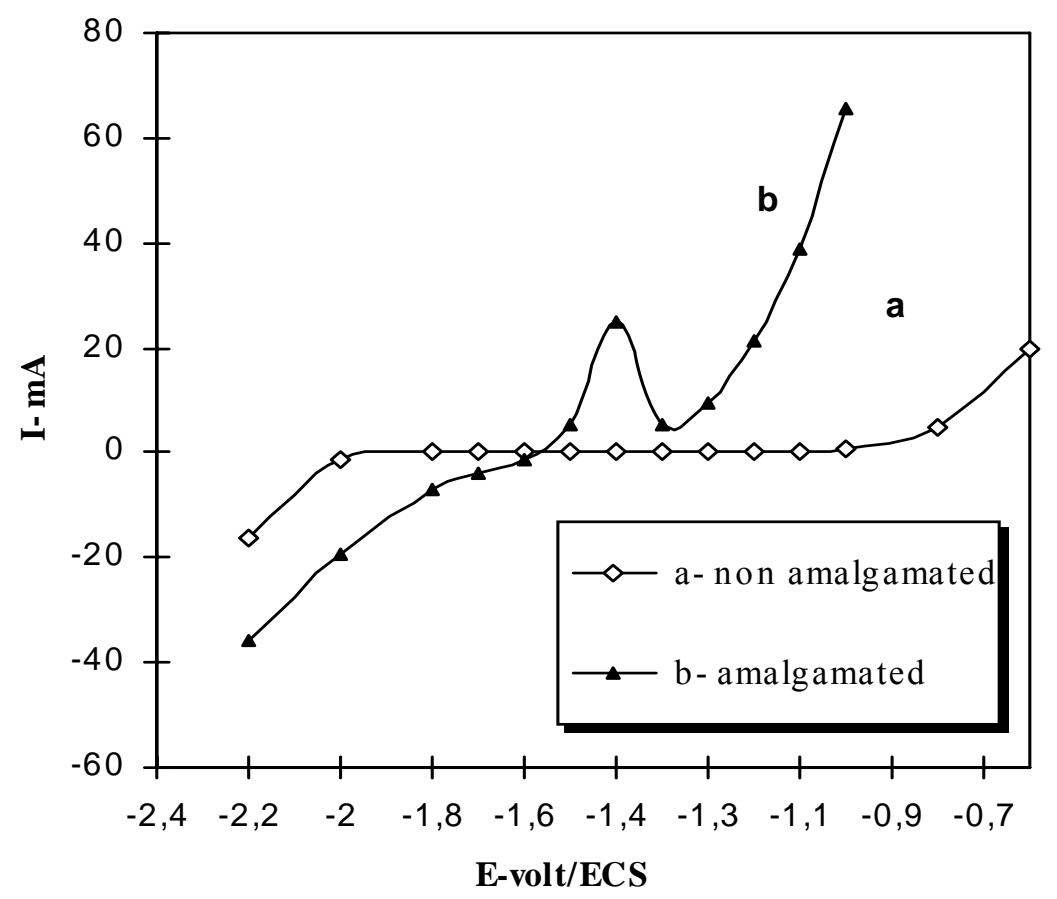

Figure 1: Voltamograms for amalgamated and non amalgamated alloy AA5083 in $1 \mathrm{M} \mathrm{KCl}$

\section{Electrochemical behaviour of amalgamated alloy}

Figure 1, curve b represents the electrochemical behaviour of alloy AA5083 after 10min of preamalgamation in a separated cell at constant potential of $-0,15 \mathrm{volt} / \mathrm{SCE}$, and after $6 \mathrm{~min}$ of immersion in the experimental electrolyte $(1 \mathrm{M} \mathrm{KCl})$ before starting scanning.

Results show an anodic oxidation peak at potential $\mathrm{E}_{\mathrm{p}}=-1.4 \mathrm{volt} / \mathrm{SCE}$, current peak was $I_{p}=25 \mathrm{~mA}$ and gave a value of corrosion potential of $\mathrm{E}_{\mathrm{cor}}=-1.6$ volt/ECS, the cathodic area shows the reduction of hydrogen.
Evolution of oxidation peak current in different experimental conditions

Three conditions were investigated: the time of immersion of amalgamated electrode, the time of mercury deposition and the scanning rate potential.

All specimens were amalgamated in $10^{-}$

${ }^{4} \mathrm{M} \mathrm{HgCl}_{2}$ solution and immersed for definite time in the experimental solution $(1 \mathrm{M} \mathrm{KCl})$.Rotation of electrode was at $5000 \mathrm{rpm}$ for all experiments. 


\section{a. Time of immersion}

Specimens were amalgamated for a period of $10 \mathrm{~min}$ and then immersed in experimental solution for: $6,18,24,30$, 42,48 and 120 minutes respectively. Scanning at $300 \mathrm{mv} / \mathrm{min}(5 \mathrm{mv} / \mathrm{s})$ was started immediately after these preliminaries.

The voltammograms (Figure 2) shows an increase in peak current $\mathrm{I}_{\mathrm{p}}$ with time of immersion.
A plot of the peak current $I_{p}$ with immersion time shows two zones (Figure $3)$ : the first zone at a time less than 36 min, the curve was nonlinear and it increased rapidly at $233 \mu \mathrm{A} / \mathrm{min}$; the second zone at a time beyond $36 \mathrm{~min}$, variation of $I_{P}$ becomes linear and stabilised at a low increment of $21 \mu \mathrm{A}$ /min.

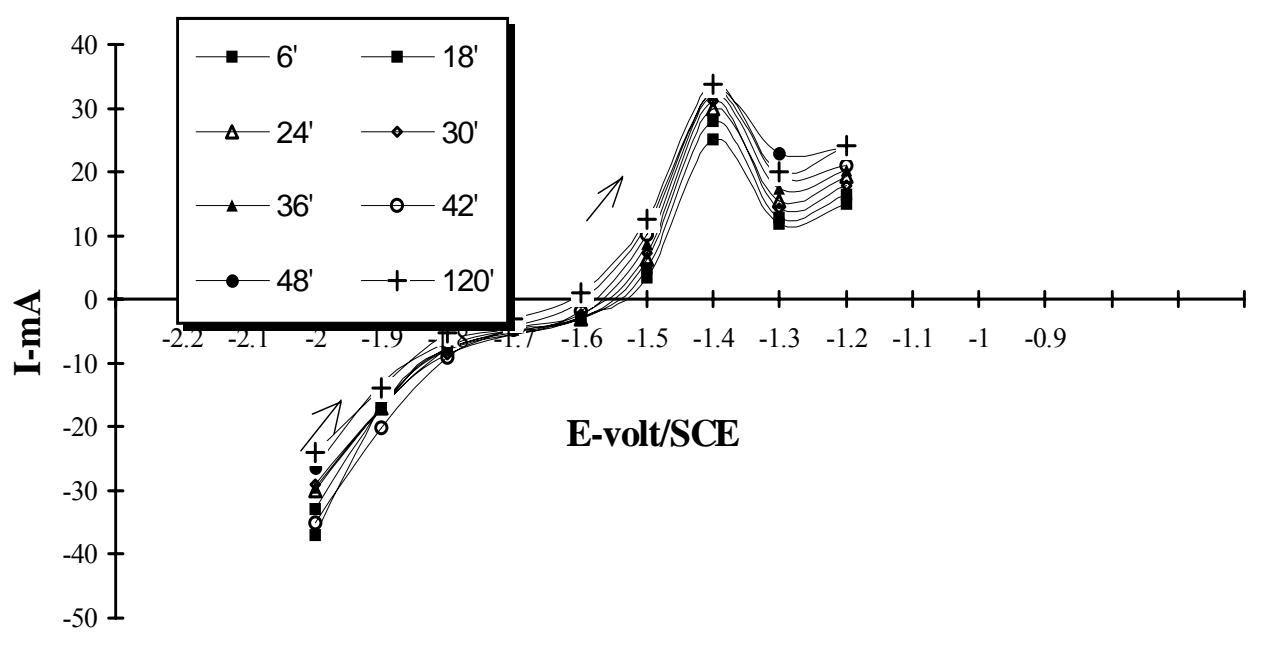

Figure 2: Voltamogram for amalgamated alloy AA5083 in $\mathrm{KCl} 1 \mathrm{M}$ for different times for immersion

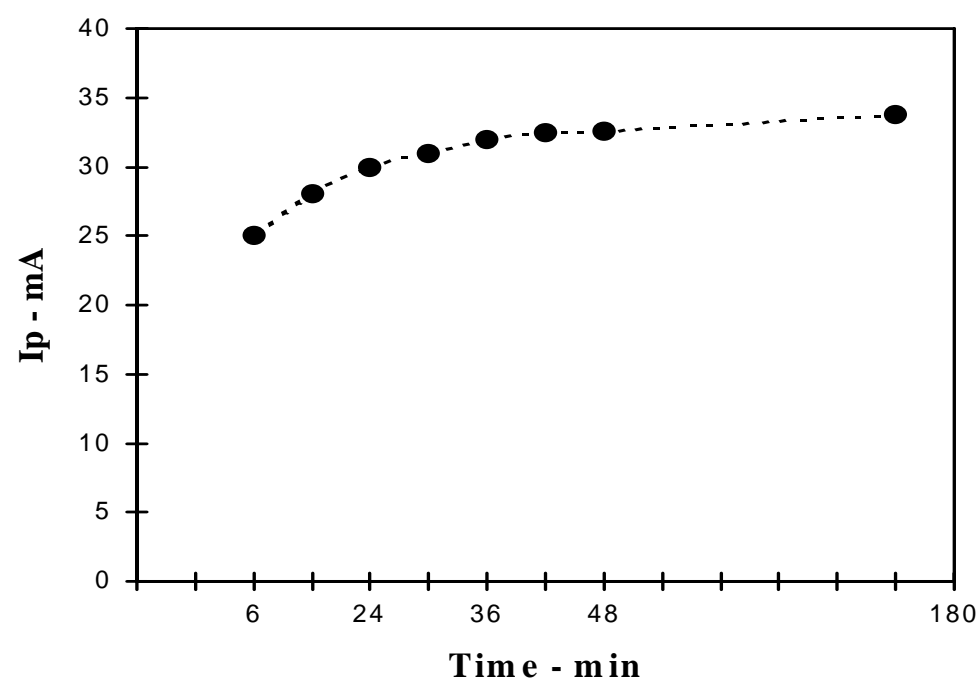

Figure 3: Peak current vs Immersion time 


\section{b.Time of amalgamation}

Electrodes were amalgamated in $10^{-4} \mathrm{M}$ $\mathrm{HgCl}_{2}$ solutions at different times, $\mathrm{t}=6$, $18,24,30,36,42$ and $48 \mathrm{~min}$ respectively; then they were immersed in an experimental solution of $\mathrm{KCl}(1 \mathrm{M})$ for $30 \mathrm{~min}$ at a potential scan rate of 300 $\mathrm{mv} / \mathrm{min}(5 \mathrm{mv} / \mathrm{s})$ and electrode rotation rate of $5000 \mathrm{rpm}$.

Results in Figure 4 show an increase in amplitude of peak current with amalgamation time.
The dependence of peak current on time in Figure 5 exhibited two parts: the first one is at a time less than $30 \mathrm{~min}$, the peak current increases linearly with rate of mercury deposition; the second part of the curve corresponding to time longer than $30 \mathrm{~min}$, peak current tends to stabilise indicating a complete electrolysis of mercury .

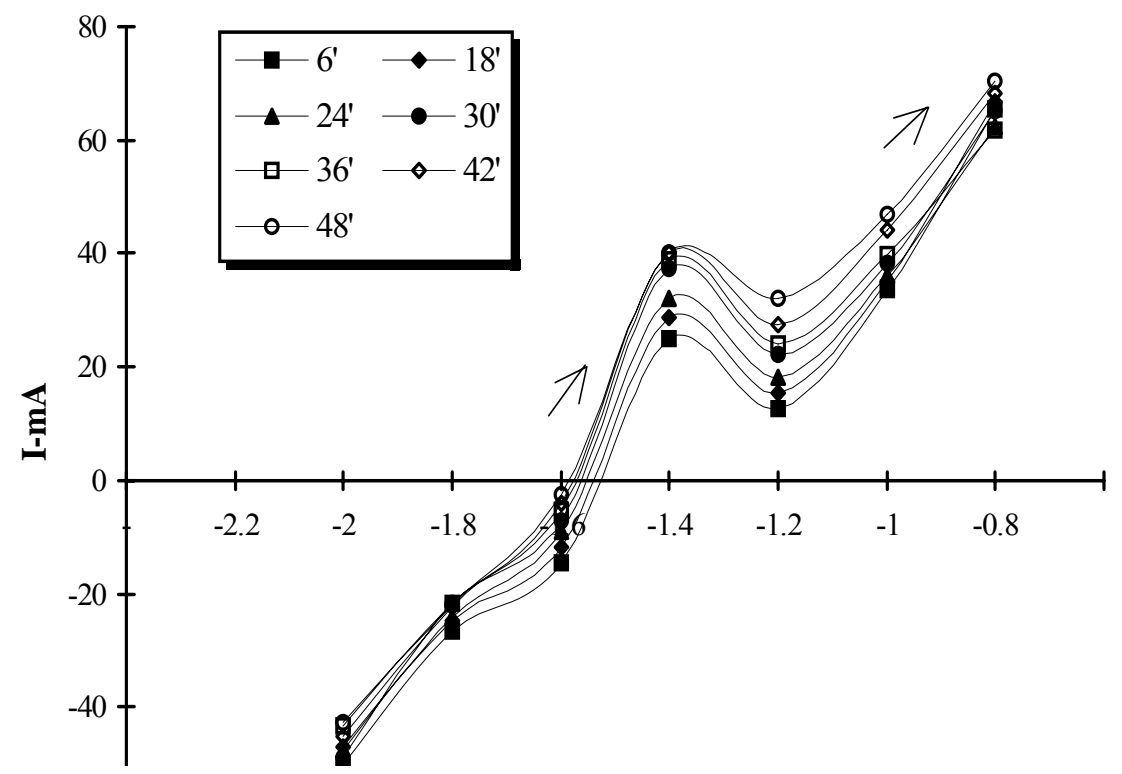

Figure 4 : voltamogram of alloy AA5083 for different amalgamation times

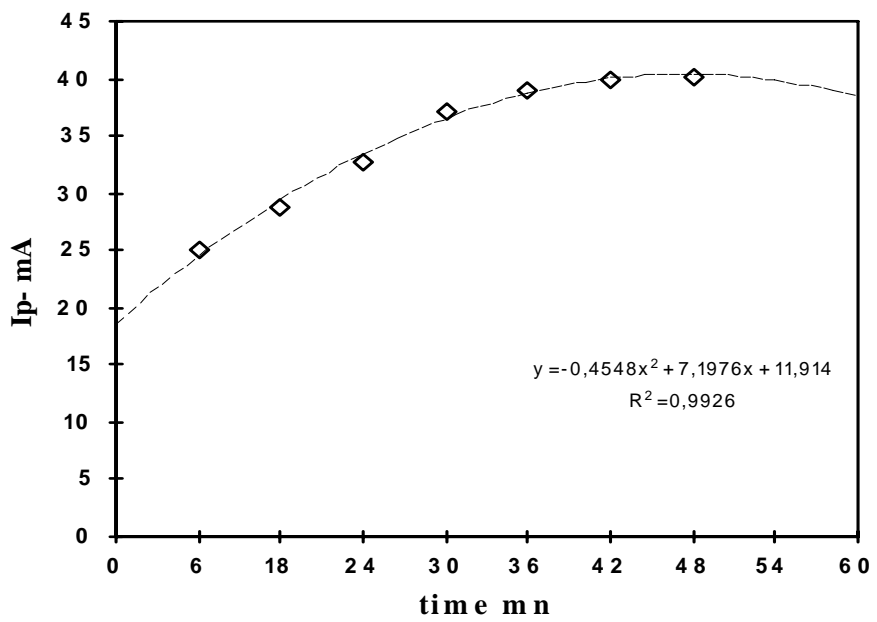

Figure 5 : current peak evolution vs time amalgamation 


\section{c. Scanning rate potential}

Electrodes were amalgamated in $10^{-4} \mathrm{M}$ $\mathrm{HgCl}_{2}$ solution for $30 \mathrm{~min}$ an then immersed in experimental electrolyte for 36 min .Times adopted corresponded to the second part of the curves of Figures 3 and 5 . Scanning rates were $\mathrm{v}=50,100$, $200,300,500,800,1000 \mathrm{mv} / \mathrm{min}$.
Results in Figure 6 show a decay of peak with increase in scan rate.

For scanning rates $\mathrm{v}<100 \mathrm{mv} / \mathrm{min}$, the slope was $\frac{d I_{p}}{d v}=-0.27 \mathrm{~mA} / \mathrm{mv}-\mathrm{mn}$

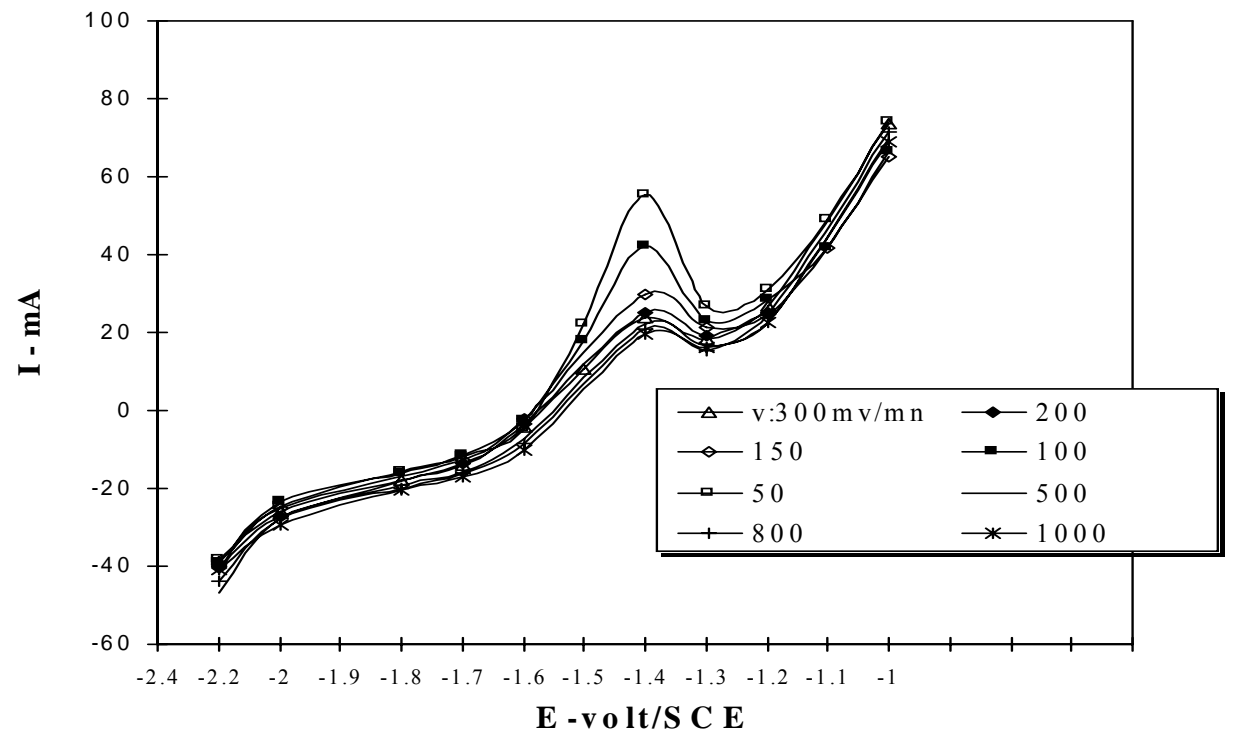

Figure 6: voltamograms for different scanning potentials

Variation of $I_{p}$ with potential scan rate is represented in Figure 7 which shows two linear different dependences: For relatively low scanning rates, $\mathrm{v}<100$ $\mathrm{mv} / \mathrm{min}$, the decay was $\frac{d I_{p}}{d v}=-0.27 \mathrm{~mA} / \mathrm{mv}-\mathrm{mn}$
For the rates higher than $300 \mathrm{mv} / \mathrm{min}$, the variation was much slower with a decay of $\frac{d I_{p}}{d v}=-0,013 \mathrm{~mA} / \mathrm{mv}-\mathrm{mn}$ 


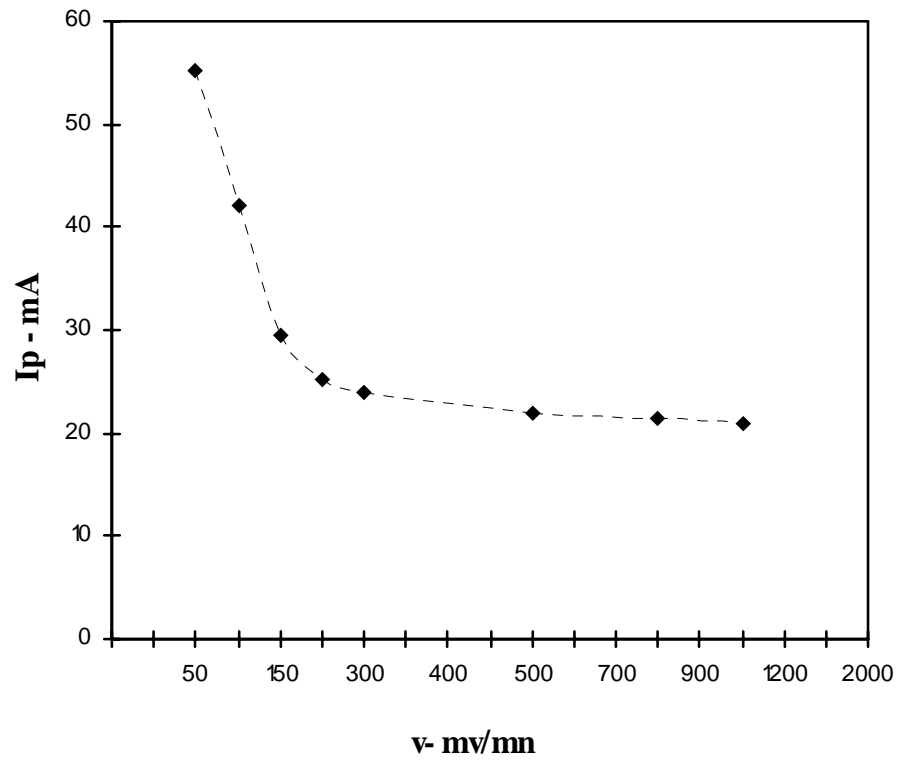

Figure 7:Peak current vs. potential scanning rates

\section{Corrosion potential}

Corrosion potential showed a negative value -1.52 volt to -1.60 volt $/ \mathrm{SCE}$ and depended on experimental conditions.

Corrosion potential was shifted towards more negative values for longer time of immersion (Figure 8 ).

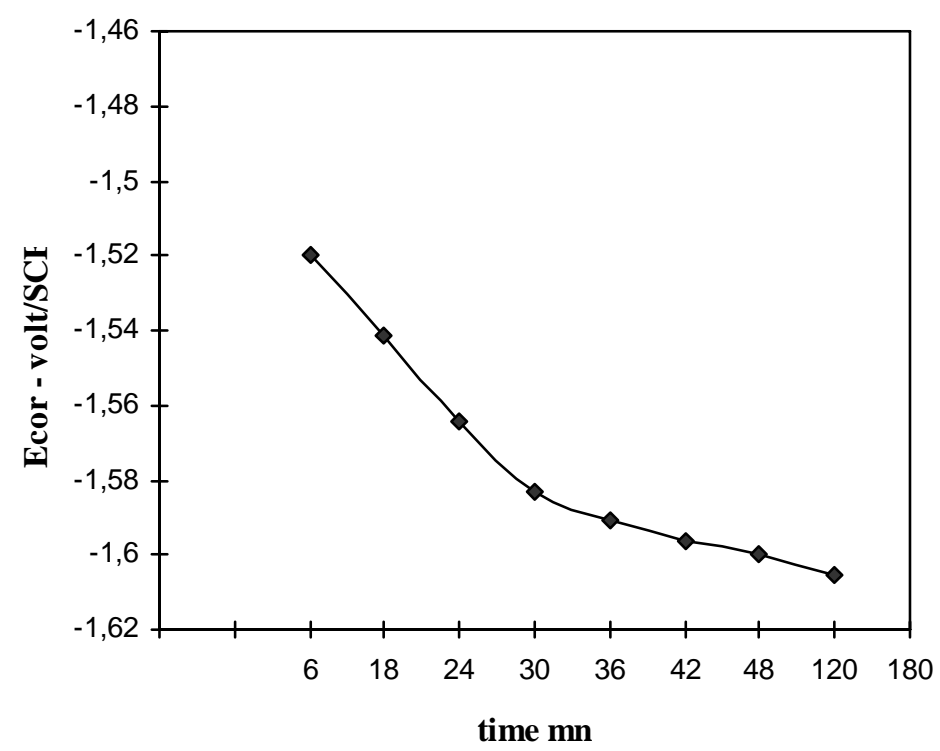

Figure 8: $\mathrm{E}_{\text {cor }}$ vs. time immersion 


\section{DISCUSSION}

Corrosion of industrial aluminium alloy AA5083 in neutral aqueous medium

a spontaneous passivity and then deactivation (Figure 1a).

A different behaviour was unregistered when electrode was amalgamated, voltammograms showed, in their anodic area, an oxidation peak at a potential $\mathrm{E}_{\mathrm{p}}=$ -1.4 volt /ECS, attributed to the reaction ${ }^{7}$

$$
\mathrm{Al}((\mathrm{Hg}))+3 \mathrm{H}_{2} \mathrm{O}=\mathrm{Al}(\mathrm{OH})_{3}+3 \mathrm{e}^{-}+3 \mathrm{H}^{+}
$$$$
+\mathrm{Hg}
$$

Reaction (1) is well known and showed a catalytic reaction in which mercury is regenerated from the amalgam and will continue the process of amalgamation .This reaction occurs at the amalgam /water interface as indicated in Figure 9 and is electrochemically dependent . containing chloride showed a complex process on amalgamation.

The non amalgamated alloy exhibited a classical electrochemical behaviour with Amalgamation of aluminium (reaction2) is a chemical process which obeys a chemical kinetic with a rate constant, kc, occurring at the interface amalgam /bulk aluminium interface.

$$
\mathrm{Al}+\mathrm{Hg}=\mathrm{Al}((\mathrm{Hg}))
$$

Reaction 2 reached a stationary level when the amalgam becomes aluminium saturated. However, reaction 1 is an aluminium consumer and a gradient of aluminium concentration occurs and a diffusion process takes place.

The scheme of the general process is represented in Figure 9.

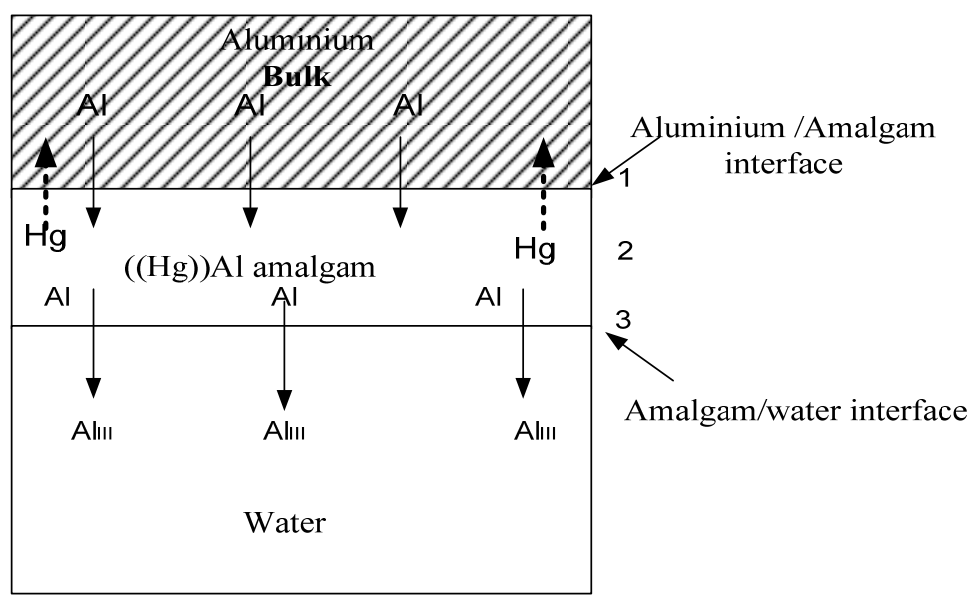

1 - Chemical reaction : $\mathrm{Al}+\mathrm{Hg}=((\mathrm{Hg})) \mathrm{Al}$

2- Diffusion of $\mathrm{Al}$ in Mercury

3- Electrochemical oxydation of Aluminium : $\mathrm{Al}=\mathrm{Al}_{\mathrm{III}}+3 \mathrm{e}$

Figure 9: process of aluminium corrosion induced by Mercury

The two parts unregistered on curves in Figures 3, 5 and 6 showed 2 determinant steps in the process.
At short immersion times of direct contact of mercury with the active surface of aluminium, amalgamation (Reaction 2) 
is a controlled process while, at a longer period of direct contact, the amalgam tends to be saturated according to solubility of aluminium in mercury and then diffusion of aluminium which controls the general process sets in.

During the amalgamation period, chemical process controls the general kinetics, because the rate of mercury deposition on electrode increases and the saturation cannot occur before the total electrolysis of mercury ions. However, for a determined concentration of mercury solution, total electrolysis occurs at a limited period and then diffusion control takes over.

Variation of $I_{p}$ with potential scan rates showed the impact of chemical and diffusion steps on electrochemical corrosion.

At low scan rate diffusion controlled the process (first part of figure 7) but at higher values, the process becomes chemically dependent. Peak current in similar cases (thin film of mercury) is given by the relation ${ }^{8}$

$$
\mathrm{I}_{\mathrm{p}}=\mathrm{n}^{2} \mathrm{~F}^{2} / \mathrm{v} / 1 \mathrm{~A} \mathrm{C} \mathrm{Al}_{((\mathrm{Hg}))} / 2.7 \mathrm{R} \mathrm{T}
$$

For a total electrolysis of $50 \mathrm{ml}$ of $\mathrm{Hg}^{++}$ solution, the calculated thickness of the amalgam, l, was $10.05 \mu \mathrm{m}$ for a surface of electrode of $7.06 \mathrm{~mm}^{2}$. Slope of the function $\mathrm{I}_{\mathrm{p}}$ vs has a value of $-0.27 \mathrm{~mA} /$ millivolt $/ \mathrm{min}$ or 0.00021 A.s / volt ( figure7) .The deduced concentration $\mathrm{C}_{\mathrm{Al}((\mathrm{Hg}))}$ at the amalgam /water interface was approximately $1 \mathrm{mg} / 100 \mathrm{~g}$ of mercury.

The literature ${ }^{8}$ saturation concentration of aluminium in mercury at $20^{\circ} \mathrm{C}$, is $2 \mathrm{mg}$ $/ 100 \mathrm{~g}$ of mercury.

The aluminium concentration profile in the amalgam ${ }^{(8)}$ is presented in Figure 10.

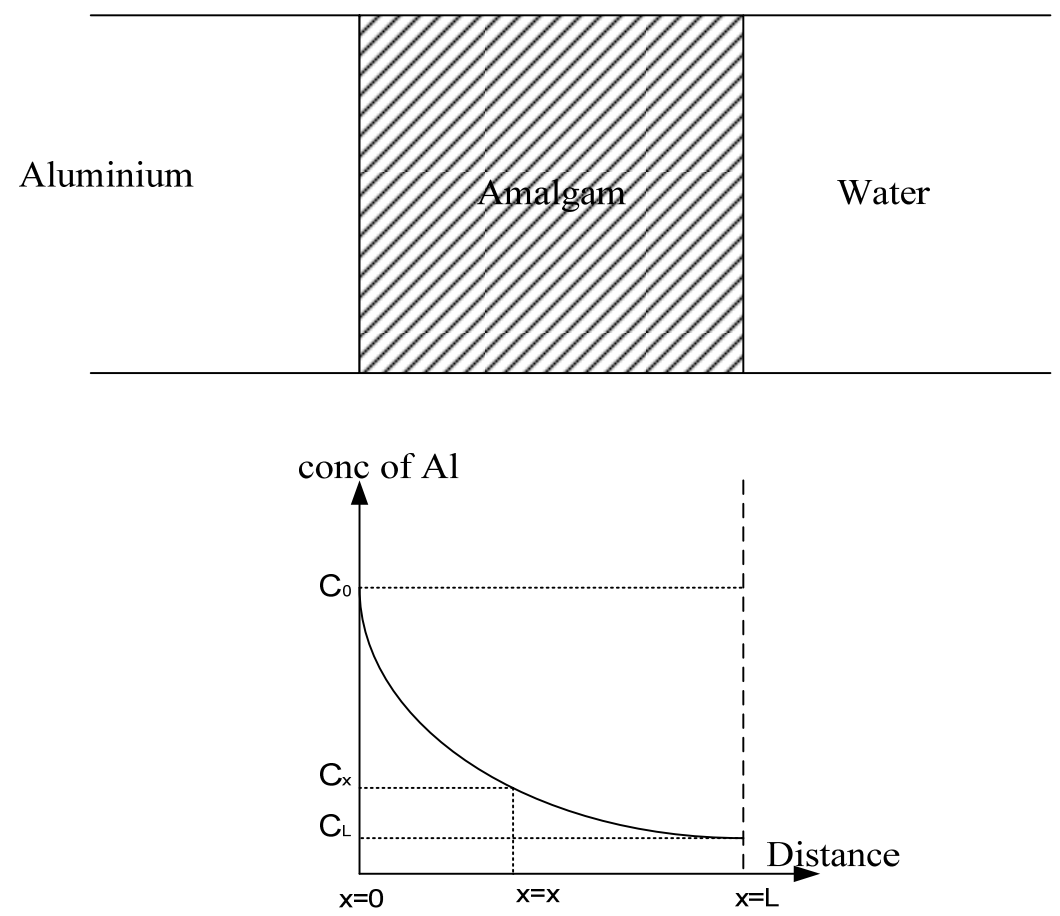

Figure 10: Profile of concentration of aluminium in amalgam

\section{CONCLUSION}

Electrochemical corrosion studies of industrial aluminium alloy AA 5083 in natural gas containing mercury metal and water as impurities showed to be a complex process. Single scan voltamograms of amalgamated electrode showed electrochemical oxidation peaks around $\mathrm{E}=-1.4$ volt $/ \mathrm{SCE}$ and a 
corrosion potential $\mathrm{E}_{\mathrm{cor}}=-1.6 \mathrm{volt} / \mathrm{SCE}$ showing an active amalgamated surface.

Oxidation peak, Ip, relating rate of electrochemical oxidation of aluminium was dependent on three factors including thickness of amalgam, diffusivity of aluminium in amalgam and rate of chemical dissolution of aluminium in mercury which is the limiting step at high scanning rate potential and low immersion time.Diffusion step which controls kinetics at highest immersion time and lowest scanning rate and an intermediate step which controlled the two kinetics.

\section{REFERENCES}

1. Kinney, G. T. 1975. Oil and Gas.

2 Phannensteil, L. L., Kinley, M. C. and Sorensen,J.C. XIV international congress of refrigeration, 1976.

Huitième congrès international sur le gaz naturel, 1986. session 2, (5) : 15-19.

4 S. Wongkasemjit, A. Wasantakorn, 2000. J.Corr. Sci.Eng.(1).

5 M. Rebouh, M. Delatte,. Revue de l'aluminium 511 (1981) 417.

6 J. E. Bennet, M R Pinnel ,. J. of Mat. Sci. 2 (1974) 338.

8. A.J.Bard ,L.R.Faulkner, 1983. Electrochimie: principes, méthodes et applications, 466- 475 . 